\title{
BMJ Open Patient and system factors of time to surgery after hip fracture: a scoping review
}

\author{
Katie J Sheehan, ${ }^{1}$ Boris Sobolev, ${ }^{2}$ Yuri F Villán Villán, ${ }^{3}$ Pierre Guy ${ }^{4}$
}

To cite: Sheehan KJ, Sobolev B, Villán Villán YF, et al. Patient and system factors of time to surgery after hip fracture: a scoping review. BMJ Open 2017;7:e016939. doi:10.1136/ bmjopen-2017-016939

- Supplementary file: Pubmed search to identify factors of time to hip fracture surgery

- Prepublication history and additional material for this paper are available online. To view these files please visit the journal online (http://dx.doi. org/10.1136/bmjopen-2017016939).

Received 20 March 2017 Accepted 25 April 2017

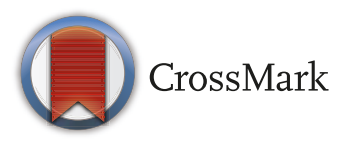

${ }^{1}$ Academic Department of Physiotherapy, Division of Health and Social Care Research, King's College London, London, UK

${ }^{2}$ School of Population and Public Health, University of British Columbia, Vancouver, Canada ${ }^{3}$ Hospital Universitario La Paz, Madrid, Spain

${ }^{4}$ Centre for Hip Health and Mobility, University of British Columbia, Vancouver, Canada

Correspondence to

Katie J Sheehan;

katie.sheehan@kcl.ac.uk

\section{ABSTRACT}

Objectives It is disputed whether the time a patient waits for surgery after hip fracture increases the risk of in-hospital death. This uncertainty matters as access to surgery following hip fracture may be underprioritised due to a lack of definitive evidence. Uncertainty in the available evidence may be due to differences in characteristics of patients, their injury and their care. We summarised the literature on patients and system factors associated with time to surgery, and collated proposed mechanisms for the associations.

Methods We used the framework developed by Arksey and 0'Malley and Levac et al for synthesis of factors and mechanisms of time to surgery after hip fracture in adults aged $>50$ years, published in English, between 1 January 2000 and 28 February 2017, and indexed in MEDLINE, EMBASE, CINAHL or Ageline. Proposed mechanisms for reported associations were extracted from discussion sections.

Results We summarised evidence from 26 articles that reported on 24 patient and system factors of time to surgery post hip fracture. In total, 16 factors were reported by only one article. For 16 factors we found proposed mechanisms for their association with time to surgery which included surgical readiness, available resources, prioritisation and out-of-hours admission.

Conclusions We identified patient and system factors associated with time to surgery after hip fracture. This new knowledge will inform evaluation of the putative timingdeath association. Future interventions should be designed to influence factors with modifiable mechanisms for delay.

\section{INTRODUCTION}

Surgery for hip fracture carries a significant risk of death with $7 \%$ dying in hospital. ${ }^{1}$ This mortality risk depends on characteristics of patients, injury and treatment. In particular, some suggested the time a patient waits for surgery increases the risk of in-hospital death. ${ }^{23}$ Aiming at prevention of potentially harmful treatment delays, several countries set a target time for repair of hip fracture. ${ }^{4-6}$ However, others report no difference in the risk of in-hospital death with surgical delays. ${ }^{7}$ This uncertainty matters as access to surgery following hip fracture may be underprioritised due to a lack of definitive evidence.

\section{Strengths and limitations of this study}

Scoping review according to published guidelines.

- Additional information on mechanisms for reported associations.

- Full-text review and data extraction completed by two reviewers.

- Restricted to reports of usual care with regression analysis published after 1 January 2000.

- No quality appraisal of the included studies.

Uncertainty in the available evidence may be due to differences in characteristics of patients, their injury and their care. Indeed, existing evidence identified patient and system factors associated with time to surgery after hip fracture. A patient's health status on admission or their preference to discuss their options with family may delay surgery. ${ }^{8}$ Conversely, delays may result from insufficient hospital resources or other issues related to the healthcare system. ${ }^{9}$ Failure to consider the role of these other factors may lead to conclusions based on a confounded association between timing and death.

In the current literature, there is no review of factors at play, or of the underlying mechanisms for the reported associations. This knowledge is important, as it will inform evaluation of the putative timing-death association. Further, knowledge of the underlying mechanisms will inform interventions which target modifiable factors with a negative effect on time to surgery. To address the knowledge gap, we performed a scoping review, a recognised approach to clarify a complex concept and present a means to summarise the factors involved. ${ }^{10}{ }^{11}$ Therefore, the aims of this review were (1) to identify patient and system factors of timing of surgery after hip fracture, and (2) collate the proposed mechanisms for the reported associations. 


\section{METHODS}

We followed the widely recognised scoping review framework by Arksey and O'Malley ${ }^{12}$ and subsequent recommendations ${ }^{11}{ }^{13}$ for conducting and reporting scoping reviews. In keeping with this recommended framework, we collated the evidence on a topic of interest and do not critically appraise the methodology of reviewed articles. ${ }^{11-13}$

Levac et al acknowledged that scoping review research questions which are too broad in nature lacked direction, clarity and the focus needed to inform subsequent stages of the research process, such as identifying studies and making decisions about study inclusions. ${ }^{11}$ They recommend combining a broad research question with a clearly articulated scope of inquiry. ${ }^{11}$ As such we identified the broad research question "what patient and system factors are associated with timing of hip fracture surgery?' within our scope of inquiry of adults over the age of 50 years, who received usual care, after admission to acute care with non-pathological low energy hip fracture. We extended this framework by collecting information on the underlying mechanisms for found associations.

This scoping review summarised published literature and ethical approval was not required.

\section{Study selection}

One reviewer searched MEDLINE, EMBASE, CINAHL and Ageline using peer-reviewed combinations of key search terms: time to surgery, hip/femoral fracture, regression analysis and observational study design (see online supplementary file 1 ). Studies were first screened for eligibility according to title and abstract using standardised inclusion criteria (table 1). The reference list of included articles was screened for additional articles. To assess the accuracy of article selection, a second reviewer screened the first 50 studies for eligibility according to title and abstract using the standardised inclusion criteria. There was no disagreement between reviewers. Subsequent studies marked as 'maybe for inclusion' were screened by a second reviewer for eligibility. Studies that appeared suitable were selected for

\begin{tabular}{|c|c|}
\hline Term & Include \\
\hline Study population & $\begin{array}{l}\text { Men and women } \geq 50 \text { years of age with } \\
\text { non-pathological low energy hip fracture }\end{array}$ \\
\hline Study design & Observational studies \\
\hline Factors & $\begin{array}{l}\text { Patient and system factors of time to } \\
\text { surgery }\end{array}$ \\
\hline Associations & Estimates from regression analysis \\
\hline Outcome & Time to surgery \\
\hline Date & $\begin{array}{l}\text { Between } 1 \text { January } 2000 \text { and } 28 \text { February } \\
2017\end{array}$ \\
\hline Language & English \\
\hline Geography & Worldwide \\
\hline
\end{tabular}

full-text review. Full-text review and data extraction was completed by the two reviewers.

We reviewed studies published in 2000 or later to minimise the potential biassing effects of demographic ageing, ${ }^{14-17}$ surgical advancements ${ }^{15}$ and changes in delivery of hip fracture care. ${ }^{18-20}$ In particular, advances in surgical implants, care structures such as surgeon level of experience, and care processes such as discharge and access policies. ${ }^{115}$ We did not include intervention-based studies on the premise that they do not reflect time to hip fracture surgery following usual care. Finally, only studies reporting regression analysis were included as a regression model was deemed a proxy for the direction of the reported association.

Using a standardised data collection, one reviewer extracted author's name, publication date, timing of surgery relative to the hip fracture admission, and patient and system factors of time to surgery (from univariate and multivariate regression analysis) in each article. The significance of statistical associations between the factors and mortality was derived from the $95 \%$ CIs reported in the articles. The proposed mechanisms for the effect of patient and system factors on timing of surgery after hip fracture were extracted from discussions by one reviewer. The accuracy of extraction was assessed by a second reviewer.

\section{Collating, summarising and reporting results}

Patient and system factors of time to surgery studied in the reviewed articles are summarised in table 2. Factors with a proposed mechanism of their effects on time to surgery are summarised in table 3 .

\section{RESULTS}

\section{Search results}

The searches produced 930 articles for initial title and abstract screening (figure 1). We excluded 907 articles on title and abstract screening. We identified three additional articles from screening of reference lists. We included 26 articles in this review. ${ }^{91-34}$

Among the included articles, patient and system factors for timing of surgery beyond 48 hours, beyond 36 hours and beyond 24 hours were reported by $17,{ }^{9} 21$ 23-27 29-38 $1^{39}$ and $3^{22}$ studies, respectively. A further five studies reported on patient and system factors for continuous time to surgery. ${ }^{28} 40-43$

\section{Patient factors of time to surgery}

We identified 10 patient factors of time to surgery after hip fracture (table 2). Five factors (fracture type, preadmission residence, sex, concomitant pelvic fracture and functional status) were studied by only one study included in this review. There is general consensus that time to surgery after hip fracture is associated with age, anticoagulant therapy, antiplatelet therapy, clinical stability, comorbidity and socioeconomic status. One study reported no association between concomitant 


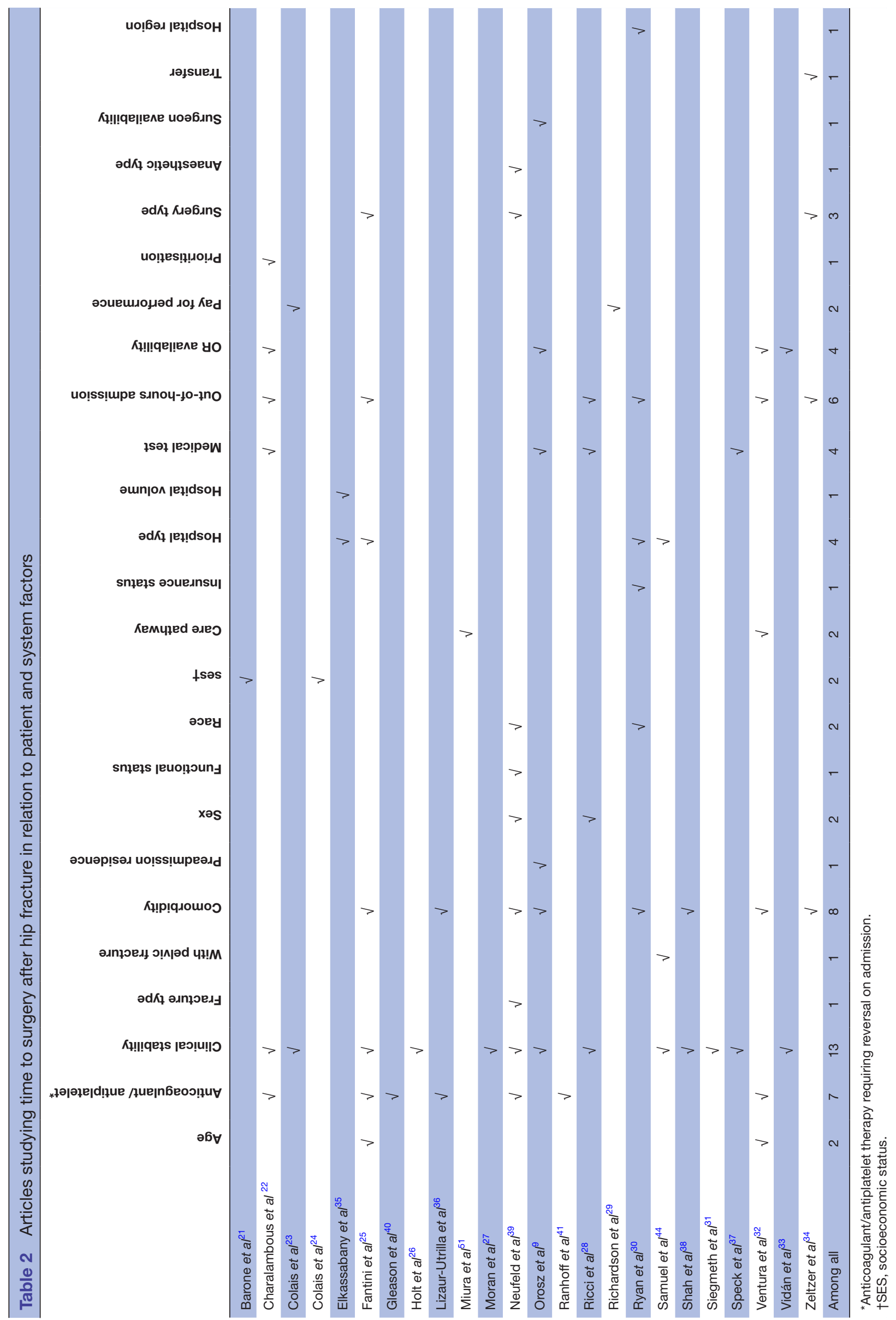




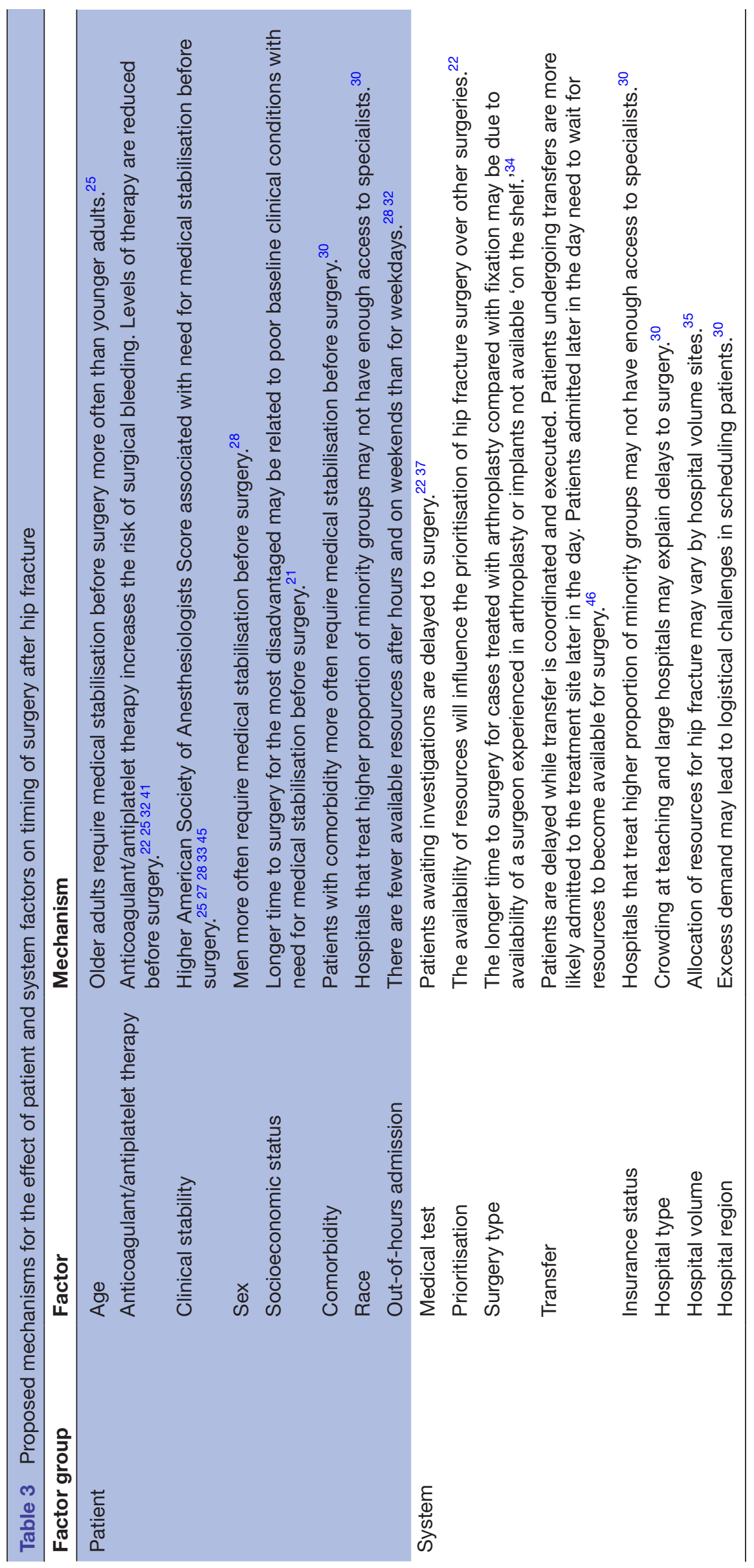




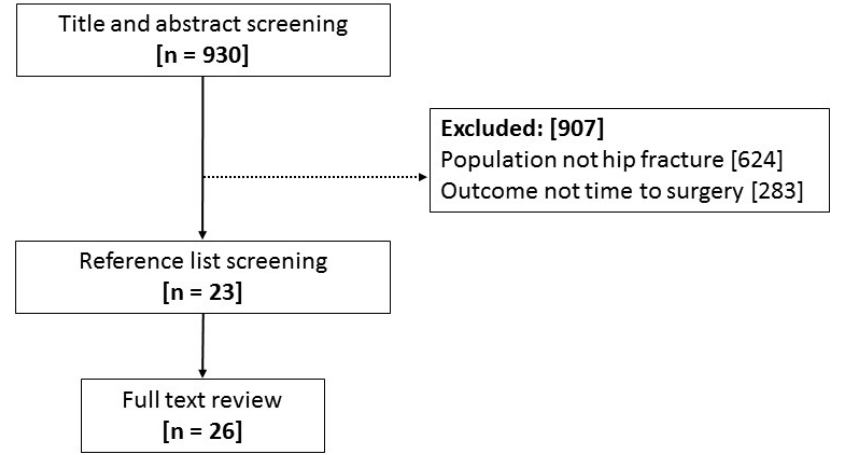

Figure 1 Flow chart of the literature retrieval, review, exclusion and selection.

upper limb fracture, injury severity score, alcoholism, or obesity and time to surgery after hip fracture. ${ }^{44} \mathrm{We}$ identified seven factors with proposed mechanisms underlying the association between patient factors and timing of surgery after hip fracture (table 3, figure 2). Surgical readiness was the proposed mechanism for the association between age, ${ }^{25}$ anticoagulant therapy, ${ }^{22} 2532$ antiplatelet therapy, ${ }^{32}$ clinical stability, ${ }^{25} 27283345$ sex,${ }^{28}$ comorbidity $^{30}$ and socioeconomic status ${ }^{21}$ with time to surgery after hip fracture. We also displayed the patient pathway that shows where the patient factors may influence the care process (figure 3 ). The majority of patient factors are determined before fracture or at the time of injury. Clinical stability is established on assessment after arrival at the emergency department.

\section{System factors of time to surgery}

We identified 14 system factors of time to surgery after hip fracture (table 2). A total of 11 factors were studied by only one study included in this review. There is general consensus that time to surgery after hip fracture is associated with out-of-hours admission, operating room availability and surgery type. One study reported no association between the need for echocardiogram and time to surgery after hip fracture. ${ }^{37}$ Two studies reported no association between clinical pathway and time to surgery after hip fracture. ${ }^{42}{ }^{43}$ We identified nine factors with proposed mechanisms underlying the association between system factors and timing of surgery after hip fracture (table 3, figure 2). Resource availability was the proposed mechanism for the association between out-ofhours admission, ${ }^{28}{ }^{32}$ medical test, ${ }^{22}$ prioritisation, ${ }^{22}$ surgery

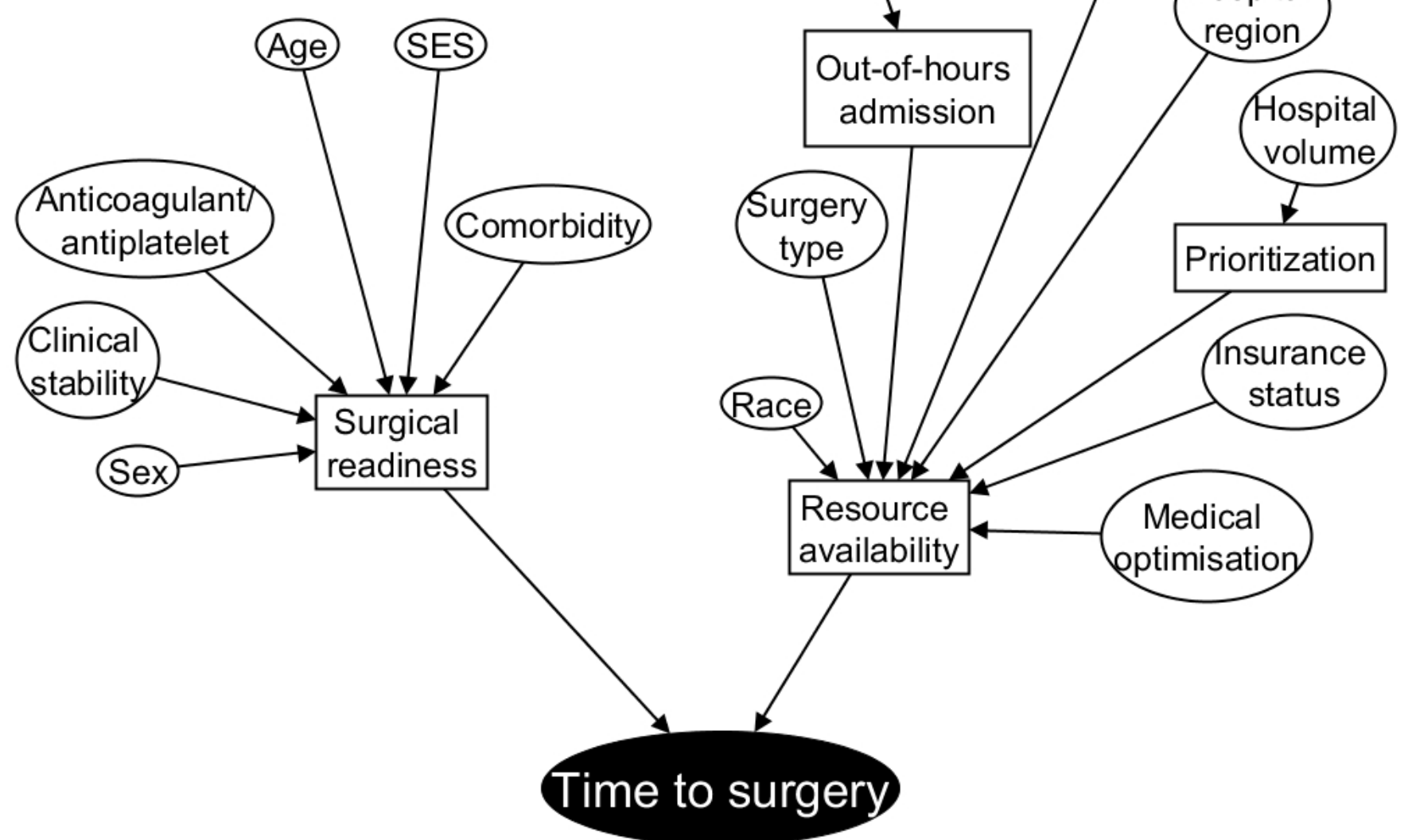

Figure 2 Mechanisms proposed for patient and system factors in reviewed articles. Black node indicates the outcome. Square box indicates a measurable mediator. SES, socioeconomic status. 


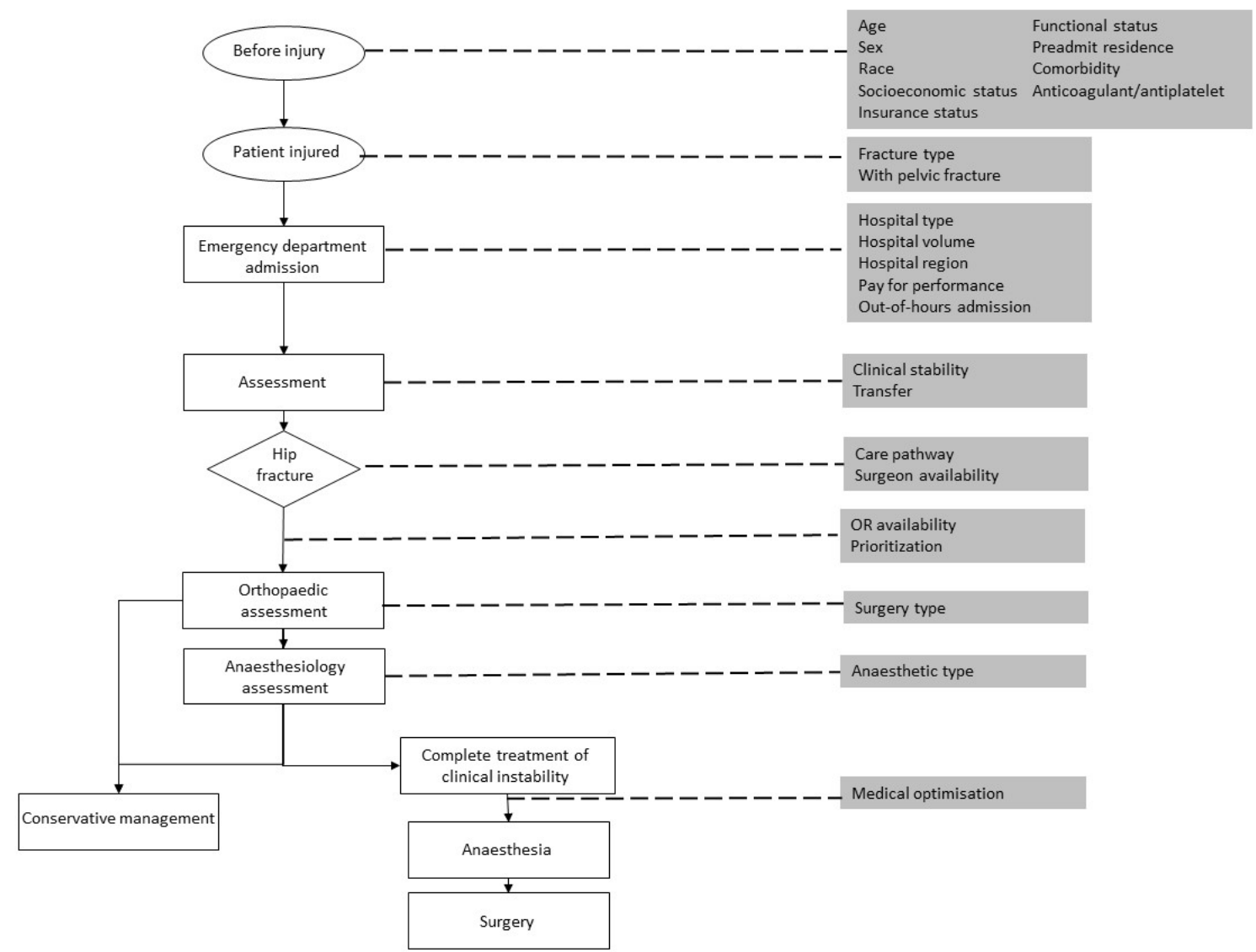

Figure 3 Example of hip fracture care process map, linked to patient and system factors associated with timing of surgery. Circles represent non-care events, white squares represent care processes, and diamond represents care diagnosis. Grey squares represent patient and system factors associated with timing of surgery.

type,$^{34}$ insurance status ${ }^{30}$ and hospital type and region ${ }^{30}$ with time to surgery after hip fracture. Out-of-hours admission was the proposed mechanism for the association between transfer and time to surgery after hip fracture. ${ }^{46}$ Prioritisation was the proposed mechanism for the association between hospital volume and time to surgery. ${ }^{35}$

We also displayed the patient pathway that shows where the system factors may influence the care process (figure 3 ). Insurance status is determined before fracture. The hospital type, volume and region, payer status, and day and time of admission are established on arrival at the emergency department. Clinical stability and the need for transfer are established on assessment in the emergency department. With a diagnosis of hip fracture the care pathway is selected, and availability of surgeon experienced in the procedure determined. The patient is then prioritised according to local policy for access to the operating room. The orthopaedic and medical team assess the patient, and the type of surgery selected. The anaesthesiologist then determines the anaesthetic type. Treatment of clinical instability is completed for medical optimisation, anaesthesia and surgery.

\section{DISCUSSION}

This review summarised the information available on proposed mechanisms for reported association between patient and system factors and time to surgery after hip fracture. This review pointed to surgical readiness, available resources, demand, prioritisation and out-of-hours admission as mechanisms for the association between patient and system factors with time to surgery after hip fracture.

Patients may be appropriately delayed to surgery to enable correction of clinical instability (as distinct from stable comorbidity). ${ }^{22} 25313247-49$ However, there is no consensus on which clinical features represent appropriate delays. The clinical guideline of the UK National Institute for Health and Care Excellence suggested that patients may be appropriately delayed by the following medical conditions and treatments: anaemia, anticoagulation, volume depletion, electrolyte imbalance, uncontrolled diabetes, uncontrolled heart failure, acute cardiac arrhythmia or ischaemia, acute chest infection, or exacerbation of a chronic chest condition. ${ }^{23}$ Siegmeth and colleagues did not include exacerbation of a chronic chest condition; however, they included gastrointestinal haemorrhage, uncontrolled hypertension and need for echocardiography, as appropriate medical reasons for delay. ${ }^{31}$ The list of medical reasons for delaying hip fracture surgery proposed by Devereaux is even more extensive. ${ }^{47}$ Further, patients may choose to delay surgery for other personal reasons. There is a need for consensus on what represent appropriate delays before surgery. 
Patients admitted to care settings with less resources available such as operating room, ${ }^{92} 32$ specialist ${ }^{28} 34$ or laboratory test ${ }^{22} 2834$ experience longer time to surgery for non-medical reasons. ${ }^{50}$ These potentially avoidable longer times to surgery prolong exposure to immobilised and inflammatory states which in turn can lead to potentially fatal complications. ${ }^{50}$ Where the surgery requires additional resources such as a surgeon with arthroplasty experience or implants not available on the shelf the patient may be delayed further. ${ }^{34}$ In fact, some settings have no orthopaedic trauma service at all and patients require transfer before definitive care. ${ }^{34}$ Longer time to surgery due to resource availability may be considered inappropriate where the patient is required to wait despite being surgically ready. Future intervention studies should target these modifiable system factors for delay to ensure timely appropriate care.

There are limitations to this review. In keeping with the scoping review framework, we collated the evidence on a topic of interest and do not critically appraise the methodology of the reported studies. ${ }^{12}$ Future systematic reviews focusing on specific factors identified in this review should include an appraisal of the methodologies. We excluded articles preceding 1 January 2000 and after 28 February 2017. It is therefore possible that we under-report patient and system factors associated with the timing of hip fracture surgery. We excluded studies which did not indicate a regression analysis in their title, abstract or MeSH terms. We also excluded intervention studies as these did not reflect our scope of inquiry. It is therefore possible we excluded articles not indexed by analysis type or study design relevant to the current review. Moreover, we may have excluded secondary analyses of factors of time to surgery following usual care within intervention studies. These exclusions may relate both to factors of time to surgery after hip fracture and underlying mechanisms for their association.

\section{CONCLUSION}

We identified patient and system factors of timing of surgery and collated the proposed mechanisms for the reported associations. We concluded that surgical readiness, available resources, out-of-hours admission and prioritisation as mechanisms for the association between patient and system factors with time to surgery after hip fracture. This new knowledge may be used to inform evaluation of bias in a future systematic review of the putative timing-death association. Further, future studies should be designed to intervene on identified factors with modifiable mechanisms for delay.

Twitter @sheehakj

Acknowledgements We thank Jillian-Ashley Martin for her expertise in developing the search strategy. We thank the editor and peer reviewers for their comprehensive appraisal of the manuscript.

Contributors All authors contributed to the conception and design of the review. KJS contributed to the search development. In addition, KJS and YFVV identified papers, and completed data extraction. KJS, BS, YFVV and PG contributed to the interpretation of the data extracted. KJS and YFVV drafted the manuscript. All authors critically revised the manuscript and approved the final version for submission.

Funding This research was funded by the Centre for Clinical Epidemiology and Evaluation and the Centre for Hip Health and Mobility, Vancouver, BC, Canada. The funders had no role in the design of the review, the data collection, analysis or interpretation of the data, or in writing the manuscript.

Competing interests PG has received grants from the Canadian Institutes of Health Research, the Natural Sciences and Engineering Research Council of Canada, the Canadian Foundation for Innovation and the British Columbia Specialists Services Committee for work around hip fracture care not related to this manuscript. He has also received fees from the BC Specialists Services Committee (for a provincial quality improvement project on redesign of hip fracture care) and from Stryker Orthopedics (as a product development consultant). He is a board member and shareholder of Traumis Surgical Systems Inc. and a board member of the Canadian Orthopedic Foundation. He also serves on the speakers' bureaus of AO Trauma North America and Stryker Canada. KJS, BS and YFVV declare they have no competing interests.

Patient consent Scoping review of published literature.

Provenance and peer review Not commissioned; externally peer reviewed.

Data sharing statement Data are collected from published literature, the references of which are detailed in the manuscript.

Open Access This is an Open Access article distributed in accordance with the Creative Commons Attribution Non Commercial (CC BY-NC 4.0) license, which permits others to distribute, remix, adapt, build upon this work non-commercially, and license their derivative works on different terms, provided the original work is properly cited and the use is non-commercial. See: http://creativecommons.org/ licenses/by-nc/4.0/

(C) Article author(s) (or their employer(s) unless otherwise stated in the text of the article) 2017. All rights reserved. No commercial use is permitted unless otherwise expressly granted.

\section{REFERENCES}

1. Sobolev B, Guy P, Sheehan KJ, et al. Time trends in hospital stay after hip fracture in Canada, 2004-2012: database study. Arch Osteoporos 2016;11:13.

2. Simunovic N, Devereaux PJ, Sprague S, et al. Effect of early surgery after hip fracture on mortality and complications: systematic review and meta-analysis. CMAJ 2010;182:1609-16.

3. Orosz GM, Magaziner J, Hannan EL, et al. Association of timing of surgery for hip fracture and patient outcomes. JAMA 2004;291:1738-43.

4. Canadian Institute for Health Information. Health Indicators. Ottawa, ON: CIHI, 20072007.

5. National Office of Clinical Audit. Irish Hip Fracture Database National Report. 2013. https://www.noca.ie/wp-content/uploads/2015/11/ IHFD-National-Report-2014-Online-Version.pdf (accessed 29 Sep 2016).

6. Neuburger J, Currie C, Wakeman R, et al. The impact of a national clinician-led audit initiative on care and mortality after hip fracture in England: an external evaluation using time trends in non-audit data. Med Care 2015;53:686-91.

7. Belmont PJ, Garcia EJ, Romano D, et al. Risk factors for complications and in-hospital mortality following hip fractures: a study using the National Trauma Data Bank. Arch Orthop Trauma Surg 2014;134:597-604.

8. Ahmed I, Khan MA, Nayak V, et al. An evidence-based warfarin management protocol reduces surgical delay in hip fracture patients. J Orthop Traumatol 2014;15:21-7.

9. Orosz GM, Hannan EL, Magaziner J, et al. Hip fracture in the older patient: reasons for delay in hospitalization and timing of surgical repair. J Am Geriatr Soc 2002;50:1336-40.

10. Davis K, Drey N, Gould D. What are scoping studies? A review of the nursing literature. Int J Nurs Stud 2009;46:1386-400.

11. Levac D, Colquhoun H, O'Brien KK. Scoping studies: advancing the methodology. Implement Sci 2010;5:69.

12. Arksey H, O'Malley L. Scoping studies: towards a methodological framework. Int J Soc Res Methodol 2005;8:19-32.

13. Colquhoun HL, Levac $D, O^{\prime} B r i e n ~ K K$, et al. Scoping reviews: time for clarity in definition, methods, and reporting. J Clin Epidemiol 2014;67:1291-4. 
14. Cooper C, Campion G, Melton LJ. Hip fractures in the elderly: a world-wide projection. Osteoporos Int 1992;2:285-9.

15. Leung $F$, Blauth $M$, Bavonratanavech $S$. Surgery for fragility hip fracture-streamlining the process. Osteoporos Int 2010;21:519-21.

16. Baker PN, Salar O, Ollivere BJ, et al. Evolution of the hip fracture population: time to consider the future? A retrospective observational analysis. BMJ Open 2014;4:e004405.

17. Gullberg B, Johnell O, Kanis JA. World-wide projections for hip fracture. Osteoporos Int 1997;7:407-13.

18. Auais M, Morin S, Nadeau L, et al. Changes in frailty-related characteristics of the hip fracture population and their implications for healthcare services: evidence from Quebec, Canada. Osteoporos Int 2013;24:2713-24.

19. Barrett B, Way C, McDonald J, et al. Hospital utilization, efficiency and access to care during and shortly after restructuring acute care in Newfoundland and Labrador. J Health Serv Res Policy 2005;10Suppl 2:31-7.

20. Suhm N, Kaelin R, Studer P, et al. Orthogeriatric care pathway: a prospective survey of impact on length of stay, mortality and institutionalisation. Arch Orthop Trauma Surg 2014;134:1261-9.

21. Barone AP, Fusco D, Colais $P$, et al. Effects of socioeconomic position on 30-day mortality and wait for surgery after hip fracture. Int J Qual Health Care 2009;21:379-86.

22. Charalambous CP, Yarwood S, Paschalides $\mathrm{C}$, et al. Factors delaying surgical treatment of hip fractures in elderly patients. Ann $R$ Coll Surg Engl 2003;85:117-9.

23. Colais P, Pinnarelli L, Fusco D, et al. The impact of a pay-forperformance system on timing to hip fracture surgery: experience from the Lazio Region (Italy). BMC Health Serv Res 2013;13:393.

24. Colais P, Agabiti N, Fusco D, et al. Inequality in 30-day mortality and the wait for surgery after hip fracture: the impact of the regional health care evaluation program in Lazio (Italy). Int J Qual Health Care 2013;25:239-47.

25. Fantini MP, Fabbri G, Laus M, et al. Determinants of surgical delay for hip fracture. Surgeon 2011;9:130-4.

26. Holt G, Smith R, Duncan K, et al. Does delay to theatre for medical reasons affect the peri-operative mortality in patients with a fracture of the hip? J Bone Joint Surg Br 2010;92:835-41.

27. Moran CG, Wenn RT, Sikand M, et al. Early mortality after hip fracture: is delay before surgery important? J Bone Joint Surg Am 2005;87:483-9.

28. Ricci WM, Brandt A, McAndrew $C$, et al. Factors affecting delay to surgery and length of stay for patients with hip fracture. $J$ Orthop Trauma 2015;29:e109-e114.

29. Richardson KK, Cram P, Vaughan-Sarrazin M, et al. Fee-based care is important for access to prompt treatment of hip fractures among veterans. Clin Orthop Relat Res 2013;471:1047-53.

30. Ryan DJ, Yoshihara H, Yoneoka D, et al. Delay in hip fracture surgery: an analysis of patient-specific and hospital-specific risk factors. $J$ Orthop Trauma 2015;29:343-8.

31. Siegmeth AW, Gurusamy K, Parker MJ. Delay to surgery prolongs hospital stay in patients with fractures of the proximal femur. $J$ Bone Joint Surg Br 2005;87:1123-6.

32. Ventura C, Trombetti S, Pioli G, et al. Impact of multidisciplinary hip fracture program on timing of surgery in elderly patients. Osteoporos Int 2014;25:2591-7.
33. Vidán MT, Sánchez E, Gracia Y, et al. Causes and effects of surgical delay in patients with hip fracture: a cohort study. Ann Intern Med 2011;155:226-33.

34. Zeltzer J, Mitchell RJ, Toson B, et al. Determinants of time to surgery for patients with hip fracture. ANZ J Surg 2014;84:633-8.

35. Elkassabany NM, Passarella M, Mehta S, et al. Hospital Characteristics, Inpatient Processes of Care, and readmissions of older adults with hip fractures. J Am Geriatr Soc 2016;64:1656-61.

36. Lizaur-Utrilla A, Martinez-Mendez D, Collados-Maestre I, et al. Early surgery within 2 days for hip fracture is not reliable as healthcare quality Indicator. Injury 2016;47:1530-5.

37. Speck FL, Morris RP, McAngus JK, et al. The impact of preoperative medical clearance procedures on the time to definitive surgical management of hip fractures. Curr Orthop Pract 2014;25:57-60.

38. Shah AA, Kumar S, Shakoor A, et al. Do delays in surgery affect outcomes in patients with inter-trochanteric fractures? J Pak Med Assoc 2015;65:S21-4.

39. Neufeld ME, O'Hara NN, Zhan M, et al. Timing of hip fracture surgery and 30-Day outcomes. Orthopedics 2016;39:361-8.

40. Gleason LJ, Mendelson DA, Kates SL, et al. Anticoagulation management in individuals with hip fracture. J Am Geriatr Soc 2014;62:159-64.

41. Ranhoff AH, Martinsen MI, Holvik K, et al. Use of Warfarin is associated with delay in surgery for hip fracture in older patients. Hosp Pract 2011;39:37-40.

42. Godin J, Brown C, Mardam-Bey S, et al. Two admission pathways for elderly patients with hip fracture: clinical outcomes at a single institution. Curr Orthop Practice 2015;26:387-94.

43. Kristensen PK, Thillemann TM, Søballe K, et al. Can improved quality of care explain the success of orthogeriatric units? A populationbased cohort study. Age Ageing 2016;45:66-71.

44. Samuel AM, Russo GS, Lukasiewicz AM, et al. Surgical treatment of femoral neck fractures after 24 hours in patients between the Ages of 18 and 49 is Associated with Poor Inpatient Outcomes: an analysis of 1361 patients in the National Trauma Data Bank. J Orthop Trauma 2016;30:89-94.

45. Pioli G, Lauretani F, Davoli ML, et al. Older people with hip fracture and IADL disability require earlier surgery. $J$ Gerontol A Biol Sci Med Sci 2012;67:1272-7.

46. Khan SK, Jameson SS, Avery PJ, et al. Does the timing of presentation of neck of femur fractures affect the outcome of surgical intervention. Eur J Emerg Med 2013;20:178-81.

47. Devereaux PJ. HIP fracture Accelerated Surgical TreaTment and Care tracK (HIP ATTACK) Trial. ClinicalTrialsgov identifier: NCT01344343 2013.

48. National Instittue for Health and Care Excellence. Hip fracture: management:timing of surgery. 2016. https://www nice org uk/ guidance/cg124/chapter/1-guidance\#timing-of-surgery (accessed 12 Dec 2016).

49. Aqil A, Hossain $\mathrm{F}$, Sheikh $\mathrm{H}$, et al. Achieving hip fracture surgery within 36 hours: an investigation of risk factors to surgical delay and recommendations for practice. J Orthop Traumatol 2016;17:207-13.

50. Sheehan KJ, Sobolev B, Guy P, et al. For the Canadian Collaborative Study on Hip F. In-hospital mortality after hip fracture by treatment setting. CMAJ 2016;188:1219-25.

51. Miura LN, DiPiero AR, Homer LD. Effects of a geriatrician-led hip fracture program: improvements in clinical and economic outcomes. J Am Geriatr Soc 2009;57:159-67. 